which, however, I see certain physiological objections. Where the use of the small occlusive cap is impracticable the Dutch cap is probably the next best thing.

The experience at our clinic, I think, confirms not only my own view but the view expressed some months ago by the Special Medical Research Committee of the Society of Constructive Birth Control, that the internal cap for the woman affords an adequate and satisfactory measure of contraception for normal cases. Practice in contraception, however is undoubtedly to-day in urgent need of some entirely satisfactory means for women with prolapse or abnormal cervices, and also for the incorrigibly careless, who, while perhaps approaching to the state of feeble-mindedness, are not actually feeble-minded. In addition to the thousand personally instructed cases recorded at the clinic, we have been in touch in correspondence in the last year or two with something approaching 10,000 cases, which, so far as the less complete data about these women go, appear entirely confirmatory of the personal records obtained through the clinic.

I am, Sir, yours faithfully,

61, Marlborough-road, Holloway, N. 19.

Marte C. Stopes.

** Clinical' experience ought to be recorded with the authority of the medical officer of the clinic.ED. L.

\section{? CAUSE OF DEATH.}

To the Editor of ThE LANCET.

Sir,- - In reference to Dr. Henry Bird's letter in THE LANCET last week, from the position in which the body was found it seems possible that death resulted from a dislocation of the neck. Were the vertebræe examined p.m.?

I am, Sir, yours faithfully,

Wylam-on-Tyne, August 5th, 1922. W. H. BrshoP.

\section{THIRST AND RECTAL SALINES.}

\section{To the Editor of THE LANCET.}

Sir,-It must be apparent to all fellow-students of Dr. Doreen Stranger (THE LANCE'1, August 5th, p. 304) that she has sacrificed hospital attendance for private research, for the administration of water instead of saline per rectum has been practised and vigorously taught in at least one clinic at Edinburgh Royal Infirmary for some years.

I am, Sir, yours faithfully,

EDMUND R. BOyd (H.S.).

County Hospital, Huntingdon, August 5th, 1922

\section{THE HOT OPERATING THEATRE.}

\section{To the Editor of THE LANCET.}

SIR,-I have for many years run my private operating theatre on the lines advocated by $\mathrm{Mr}$. R. P. Rowlands in the last issue of THE LANCET, and can corroborate his conclusions in nearly every detail. An atmosphere which, owing to its excessive heat and moisture, reduces surgeons and nurses to the consistency of a boiled rag, cannot be other than harmful to a patient whose resisting powers have been reduced by disease or injury plus an anresthetic. Even in recently constructed theatres it is quite common to find that steam from the sterilisers finds its way into the air of the theatre.

The principle of applying the heat where it is required-i.e., to the patient-instead of to all the contents of the theatre, has not yet met with general acceptance. A very moderate amount of external heating suffices for a patient who is placed on the table in fairly good general condition and whose vitality is not depressed during the operation by chill from exposure, severe loss of blood, trauma from rough operating, or over-anæsthetisation. For supplying the patient with heat the electricallyheated table is the best. In tables heated by cans or bags of hot water, the heat lessens as the operation proceeds, and is least at the end of the operation, the very time at which the patient requires it most.

For warming the theatre itself to a reasonable temperature, the old-fashioned radiator, still to be seen in recently built theatres, is far too much of a dust trap. The heating apparatus should be built into, and should form part of, the plane surface of the wall. Flat metal plates, electrically heated, answer admirably. Ventilation, in practice, resolves itself into either sucking the foul air out, its place being taken by air, more or less vitiated, from the rooms and corridors adjacent to the theatre, or diluting the foul air by driving in a continuous stream of out-door air. filtered, and if necessary warmed, the excess of air escaping from the theatre into parts of the building adjoining the theatre. The driving-in method is by far the better.

In July, 1914, the writer was in a newly built English theatre, which was being "ventilated" by an enormous extracting fan. The workers and the spectators found the atmosphere intolerable. Fortunately, the architect, in a moment of mental aberration, had fitted the theatre with an ordinary sash-frame window, which had to be opened to its fullest extent before the impending asphyxia could be obviated. - I am Sir, yours faithfully,

C. HaMilton Whiteford.

Plymouth, August 5th, 1922.

\section{THE MEDICAL DIRECTORY, 1923.}

To the Editor of THE LANCET.

SIR, - The annual circular has been posted to every member of the medical profession. Most of the returns have already been received. If any practitioner has not yet sent us the latest information, we shall be glad to receive it by an early post. We are, Sir, yours faithfully,

7, Great Marlborough-street, London, W. 1 THE EDITORS. August 2nd, 1922 .

\section{NIGHT SWEATS}

To the Editor of THE LANCET.

SIR,--The valuable communication on this subject by Dr. Marcus Paterson, in your isue of July 29th, calls for some comment, not because the statements therein are inaccurate, but because they give a wrong impression as to the frequency of night sweats in cases of pulmonary tuberculosis under proper hygienic conditions. Tuberculous patients very often give a history of profuse slumber-sweats; but in my experience such sweating is very rare under "sanatorium conditions."

When I was a visiting physician at the Mount Vernon Hospital for Diseases of the Chest, at Hampstead, about the time when the open-air wards were opened, I once asked the R.M.O. to look out some cases of night sweats, in order that I might study the circumstances with the consent of my colleagues; he could, however, only find three recent cases in the hospital, one of which had ceased to sweat at night, one had left the hospital a week before, and the third had just died. There were no cases amongst my own in-patients there. During the first 11 years of the existence of the Crooksbury Sanatorium, when I was directly responsible for the treatment, night sweats were equally rare. Out of 411 consecutive cases treated there between 1900 and 1911, only three had profuse night sweats after the first few days; and all three had extensive lesions and much constitutional disturbance. One of my colleagues there asked, on joining me, to have a supply of special pills for use in case of night sweats. There was, however, never any occasion to use a single one, and they remained untouched in the surgery. Both at Mount Vernon Hospital and at the Crooksbury Sanatorium at that time (1896-1911), the majority of cases admitted had extensive active lesions with fever; but with proper ventilation and good beds night sweats were decidedly rare. 
Nine years' subsequent experience as tuberculosis officer, during which I have had several thousand cases under observation, has confirmed me in the opinion that patients with pulmonary tuberculosis do not usually sweat profusely unless they have too warm bedclothes, or the ventilation of their quarters is mismanaged. I agree with Dr. Paterson that night sweats are not peculiar to tuberculosis. I have met with instances amongst apparently healthy returned soldiers, and often failed to get even the history of night sweats from undoubtedly tuberculous persons ; so that the symptom is not of much value in diagnosis.

Dr. Paterson's explanation of the mechanism of the symptom is probably correct; but his experience of its frequency at Colindale is singularly different from my own in Surrey. His communication rather suggests-probably unintentionally-that the use of a particular kind of mat is the best remedy for night sweats. I would, however, advise practitioners to be guided preferably $b y$. Dr. Paterson's own statements in "Shibboleths of Tuberculosis," and to regard night sweats as presumptive evidence of insufficient ventilation or other hygienic blunder.

I am, Sir, yours faithfully,

$$
\text { F. R. WALTERS, }
$$

Consulting Physician to the Crooksbury Sanatorium. Pinecroft, Farnham, Surrey, August 1st, 1922.

\section{Glbituarn.}

\section{ARTHUR JOHN HARRIES, M.D. BRUX.,}

L.R.C.P. EdIN., M.R.C.S. ENG., L.S.A.

Dr. Arthur John Harries, who was formerly phy sician and lecturer on clinical dermatology to St. John's Hospital for Diseases of the Skin, Leicestersquare, and physician to the Electrical Department at the Western Skin Hospital, died on July 28th in London at the age of $66 . \quad A$ student at University College, London, he qualified in 1880 by taking the L.R.C.P. Edin., the M.R.C.S. Eng., and the L.S.A. and was appointed honorary medical officer to the Holloway and North Islington Dispensary, thereafter devoting himself entirely to the study of dermatology and the application of electricity in medicine. In 1885 he edited and translated Warlomont's Animal Vaccination, and in an appendix to that work first suggested aseptic vaccination. In 1890 he published in THE LANCET an article on cataphoric medication and cocaine as a local anæsthetic, in which he described his procedure in a case of rachialgia where it was necessary to employ the galvano-cautery in the regions of the lower cervical and upper dorsal vertebræ. In this paper he says: "In the case under consideration a 10 per cent. solution of hydrochlorate of cocaine was used; a flannel-padded positive electrode, corresponding to the size and shape to the part to be anæsthetised saturated with the solution; the larger negative electrode (soaked with salt and water) placed in a suitable position (front of thorax) and a continuous current of 25 milliampères passed steadily through the part (without reversals) for 40 minutes. As a result six consecutive applications of the galvanocautère were painlessly made opposite the intervertebral spaces, each application extending two inches in length by one-eighth of an inch or more in depth." He was one of the pioneers of electrotherapeuties in England, and demonstrated at the Institution of Electrical Engineers the discomfort and fixation points for battery-produced alternating currents, making a similar demonstration for dynamo currents at the meeting of the British Association in 1890. He was the author of Lectures on Lupus, Electrolysis in Stricture, and a Manual on ElectroTherapeutics, besides making various contributions to the transactions of societies and to the medical press.

Dr. Harries, who was twice married, leaves five sons and one daughter.

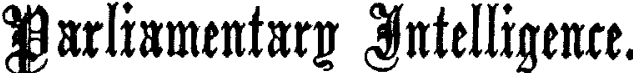

\section{NOTES ON CURRENT TOPICS.}

The Parliamentary Adjournment.

Pari.iament adjourned on Friday, August 4th, until Tuesday, Nov, 14th. The Royal Assent was given by commission to a number of Acts passed during the summer session, among which were the following: The National Health Insurance Bill ; the Milk and Dairies (Amendment) Bill; the Criminal Law Amendment Bill; the Lunacy Bill; and the Local Government and Other Officers Superannuation Bill.

\section{HOUSE OF COMMONS.}

\section{Wednesday, AUGUST 2ND.}

The Indian Medical Service.

On the motion for the second reading of the Consolidated Fund (Appropriation) Bill,

Sir W. JoYNSON-HICKS said that judging from the speech which the Prime Minister made on India a few months ago, it was not intended that the painter should be cut between this country and India. The magnificent work which this country had undertaken in India would be continued and developed until the Indians were ready and able to take over complete Home Rule, they would provide India with a Government and with a service of which India might well continue to be proud. The real difficulty was that the Indianisation of the services was proceeding at too great a pace, and if it went on to the extent which many Indian politicians desired-namely, to 100 per cent.- - they might just as well say that they were no longer going to be responsible for India. Under an arrangement which had been made it was proposed that on the Indian Civil Service there should be a 48 per cent. Indianisation. That was to say, one-half of the Indian Civil Service would be Indians and only onehalf British. At the present rate of progress that would bc completed within nine years. In the case of the Indian Medical Service-perhaps the most important of all-the figures were very startling. Since 1915 there had been 174 appointments, and of these 101 had gone to Indians and
only 73 to Europeans. The Indianisation of the Indian Medical Service was proceeding so rapidly that in many parts of India it was impossible for an English official or an English commercial man in the up-country districts to obtain the services of a white doctor. The I.M.S. was really the key service of the whole British service in India. They could not expect English officials in other services to settle down there for a period of years with their wives and the possibilities of families unless they put the clock back with regard to the Indianisation of the I.M.S.

Mr. LLOYPD George (Prime Minister) said that the recent constitutional changes in India were in the nature of an experiment, but taking into account that the experiment had been in operation only a year and a half, he thought that there had been a very considerable measure of success. They must not pass a precipitate judgment on these experiments; on the other hand, he hoped that the Indian leaders would not force a precipitate judgment upon them by their action. A great deal of patience was required on both sides. One thing they must make clear - namely, that Britain would in no circumstances relinquish her responsibility in India. He felt sure that that would be a cardinal principle with any British Government that could command the confidence of the people of this country. Britain would take whatever steps were necessary to discharge or to enforce her responsibilities. They had invited the coöperation of the people of India in the discharge of their trust; but that was not in order to lead up to a final relinquishment of their trust, but with a view of bringing Indians into partnership in the discharge of that trust within the British Empire. He had looked up the statistics and he found that the total number of British civil servants in India was only 1200 , governing $315,000,000$ people. Those figures did not include the police and the Medical Service. There were 700 British police officers and 600 British medical officers. He did not believe that there was a country in the world that could produce such a triumph of government. There was no doubt that, because of the sense of disturbance and disquietude which recent events had created in India, difficulty had been experienced in obtaining recruits for the Indian Civil Service. He did not think that there was much in the difficulty as regarded medical men, or at least it was a different kind of difficulty. The difficulty in regard to medical men, a difficulty which was experienced even here-and they certainly could not get them in the Colonies-was due to the war. Young men were drafted into the army just at the time when they should have been undergoing their training, and the result was a great 